Madrygal. Revista de Estudios Gallegos

ISSN: 1138-9664

\title{
O número 304 da revista Nós: un relato contrafactual
}

\author{
Xesús Alonso Montero ${ }^{1}$
}

\section{Nota preliminar}

Para algúns eruditos, a derradeira aparición de Nós foi o número 139-144, impreso en Ourense e correspondente ó período xullo-nadal de 1935. Eses eruditos, sen excluír a algúns ilustres hemerólogos, afirman que, cando se preparaba o número seguinte (sería o 145), aconteceu en España unha sublevación reaccionaria (xullo de 1936) que decapitou o aparato institucional da II República. Engaden eses eruditos que Galicia en poucos días foi tomada pola pouta desleal do Exército e aterrorizada pola chulería e as armas da Falanxe. Precisan eses eruditos que, de agosto a decembro de 1936, Atila xa imperaba no noso país, denominado por un ilustre debuxante "Galicia mártir".

Non foi tal. Houbo, si, unha sublevación militar, que axiña foi abafada en toda España polos militares afectos e polas forzas que gañaran as eleccións do 16 de febreiro de 1936, as forzas inesquecibles do Frente Popular. Galicia, o 25 de xullo dese ano, xa era terra librada. Así pois, non foi decapitado o Seminario de Estudos Galegos, non foi suprimido o Partido Galeguista nin se tronzou a publicación da revista Nós, que publicou o número 145 en setembro de 1936. Foi nese setembro cando os políticos e parlamentarios galeguistas estudaron a fondo o texto do Estatuto de Autonomía de Galicia plebiscitado o 28 de xuño de 1936, días antes da intentona militar que fracasaba moi pouco despois. É o Estatuto que, con notables emendas positivas, foi aprobado nas Cortes Xerais o 14 de abril de 1937. Desde esa data a hoxe, dentro do marco da Constitución Española (reformulada nalgúns artigos), Galicia é gobernada por ese estatuto, que ten o asentimento da maior parte da poboación galega, cada vez máis esixente en materia social e educativa.

Xa era moi esixente o día 15 de setembro de 1951, data na que a imprenta Nós publicou o número 304 da revista homónima, un número especial dedicado ó gran poeta e periodista Manuel Curros Enríquez no primeiro centenario do seu nacemento.

\section{Cómo era Nós antes do 14 de abril de 1937?}

Así pois, a revista Nós, estreada en 1920, non interrompeu a súa publicación en 1936 nin en ningunha data posterior. $\mathrm{O}$ que hoxe nos propoñemos é comentar o número 304 por parecernos moi representativo do perfil ideolóxico asumido pola revista pouco despois de 1936. Non só se incorporaron voces novas, senón que algunhas das "clásicas" experimentaron cambios, ás veces sorprendentes. O caso máis claro foi o de Vicente Risco, o Risco capaz de escribir no ano 1921, un ano despois da aparición de Nós:

$\mathrm{Eu}$ bendigo a endogamia... Alédome cando un galego casa cunha alemá, cunha inglesa ou cunha irlandesa; dáme tristura velo casar cunha italiana ou cunha turca. Creo na selección e na euxenesia e sei das propiedades dexenerativas do mestizaxe. (A Nosa Terra, 15-11-1921) 
Ou o Risco que trazaba este diagnóstico moral en 1931:

Ser nacionalista é tomar partido polo espírito na súa loita contra a materia (...). O noso tempo preséntanos unha loita apurada entre o materialismo e o espiritualismo. O primeiro, vencido xa no mundo da cultura superior, no mundo da filosofía e da ciencia, coa caída do derwinismo, do kantismo, da física mecanicista, etc. triunfou, non embargantes, no campo da economía, da política e dos costumes, e ameaza desfaguer tódolas institucións do Dereito natural que se conservan. (ibid. 1-3-1931).

Vicente Risco, en vésperas da apócrifa sublevación, pontificaba deste xeito:

Nós afirmamos a consubstancialidade da nosa cultura enxebre, da nosa estructura social autóctona e dos intereses morais e materiais do noso pobo labrego e mariñeiro coa concepción católica do mundo e da sociedade humán... e por iso proclamamos a liberdade e a supremacía espiritual da Eirexa. (Heraldo de Galicia, 102-1936).

Textos semellantes ós aducidos non escasean nas páxinas de Nós, que o propio Risco dirixía e orientaba. Tamén Otero Pedrayo, nome fundamental da revista, fala, verbo dun libro do exmarxista Nicolás Berdiaeff, das "tristes furias (positivismo, socialismo, anarquía)". Nesa reseña sinala Otero que o home está afundido "no informe dos elementos inferiores da vida (marxismo, comunismo, imperio do Estado)" (Nós 28, 15-2-1927).

Das poucas mulleres que colaboran na revista, unha, Francisca Herrera Garrido, nun artigo sobre "A muller galega", pon o acento "na praga sufraxista" (Nós 6, 20-8-1921).

Quen examine cun pouco de atención os números de Nós posteriores a abril de 1937 percibirá outros matices, outras actitudes, mesmo nalgúns "clásicos" da revista. Era outro tempo sociopolítico, nalgúns aspectos de incitante modernidade. Nese contexto, certos escritores reconsideraron algúns dos seus postulados ademais de abrírense a determinadas actitudes e ideas que expuñan con entusiasmo as novas voces das Letras galegas. O número 304 de Nós, de 1951, expresa, ó seu xeito, ese tempo.

\section{Do contido do número 304 de Nós (15-4-1951)}

Daquela, os números da revista constaban de tres partes (Estudos e artigos/Creación/Recensións), pero nesta ocasión, dada a efeméride, omitiuse o capítulo das recensións en favor dunha sección monográfica dedicada á vida e á obra de Curros Enríquez. Neste artigo consigno os títulos dos traballos e o nome dos seus autores, que aparecerán, como na revista, por orde alfabética. Se procede, despois do título, farei algunha breve anotación.

\section{A. Estudos e artigos}

1. Ánxel Casal, “A ominosa «lei de fugas» na España de Primo de Rivera e no Portugal de Oliveira Salazar".

Nesta etapa, Casal, editor e impresor da revista desde 1920, colabora nalgúns números, o que non acontecera na etapa anterior. Estaba, nesta altura, moi preocupado polo tema abordado neste artigo.

2. Castelao, "Análise gramsciana da miña «Cousa da vida» ilustrada co pé «Qué comerá o Rei? Comerá... comerá... comerá... zucre»".

Cómpre aclarar que Castelao non só lera as Lettere del carcere (1947) senón que fixera unha recensión entusiasta de vinte delas traducidas ó galego polo poeta comunista Manuel Gómez del Valle.

3. Serafín Ferro, "Influxo do anarquismo nas reivindicacións dos mariñeiros galegos".

Serafín Ferro, electricista de pensamento ácrata, só era coñecido nesta altura como poeta. Un dos seus primeiros poemas publicouno, precisamente, no número 139144 de Nós.

4. Luís Iglesias (coa colaboración de Ramón María Aller), "O texto do P. Sarmiento sobre a paralaxe como modelo de texto en galego de tema científico".

Era, daquela, unha preocupación do biólogo e do astrónomo que asinan este artigo.

5. Aníbal Otero, "As peculiaridades esenciais do idioma galego ante o portugués".

Aníbal Otero era, desde 1947, catedrático de Fonética e Dialectoloxía galegas na especialidade de Filoloxía Románica da Facultade de Filosofía e Letras da Universidade de Compostela. O artigo citado aínda hoxe ameaza as premisas glotolóxicas dos filólogos lusistas de Galicia, entre eles, José Luís Rodríguez e Elías Torres Feijoo. 
6. José Otero Espasandín, "O sistema educativo na Unión Soviética e na Unión de Repúblicas Socialistas do Sur de Europa”. Hai tradución grega e a varios idiomas da URSS. A versión moldava contén un prólogo sobre o pedagogo galego no que se fala entusiasticamente da Escola pedagóxica galega, constituída por Ben-ChoShey, Albino Núñez, María Barbeito Cerviño, Luis Viñas Cortegoso, Xosé Núñez Búa e Luís Soto.

7. Ramón Otero Pedrayo e Luís Seoane, "Lectura semiolóxica do Pórtico da Gloria".

É a primeira vez que se emprega o adxectivo "semiolóxica" nun texto galego. Sabido é que o capítulo escrito por Seoane foi comentado, moi gabanciosamente, moitos anos despois, por Umberto Eco, mestre da Semioloxía europea.

8. Manuel Peña Rey, "A xinecoloxía e o feminismo".

O celebérrimo xinecólogo ourensán aborda, por primeira vez, no mundo hispano, esta cuestión.

9. Xaime Quintanilla, "O socialismo nas comunidades culturais historicamente marxinadas".

Nun apéndice reproduce poemas en sardo e en bretón nos que os seus autores manifestan o seu compromiso coas súas respectivas "linguas proletarias".

10. Vicente Risco, "Dos meus desacordos de onte e dos meus gozosos acordos de hoxe co catolicismo de Jacques Maritain".

Por certo, no número seguinte, Fernando Quiroga Palacios, párroco de Santa Eufemia (Ourense), publica unha réplica amable co título "Nin tan conservador (onte) nin tan progresista (hoxe)".

11. Lois Tobío, "Non hai democracia sen socialismo nin socialismo sen democracia".

Extenso artigo, de clara filiación marxista, bastante criticado en revistas políticas de Kiev e de Moscova.

\section{B. Homenaxe a Curros Enríquez no seu cen- tenario (1851-1951)}

1. Xesús Alonso Montero, "Comentario «in modo gramsciano» da estrofa 13 da
«Introdución» de Curros Enríquez (...fala en que os parias /.../ piden á terra o grau da cor da sangue....)".

2. Ricardo Carballo Calero, "Por qué a Virxe do Ceo fala en "dialecto" no poema "A Virxe do Cristal"?

3. Xosé Filgueira Valverde, "Era crente o autor d" "A Virxe do Cristal?"

4. Ramón Piñeiro, "Clases sociais e lingua galega na época de Curros".

Ramón Piñeiro era profesor adxunto de Hans Schneider, catedrático, en Santiago, de Historia da Lingua Galega. Foi o profesor Schneider quen, en 1946, lle dirixiu a tese de doutoramento a Piñeiro. Titulábase Historia social do idioma galego dos Reis Católicos a hoxe. Foi criticada no seu tempo pola súa concepción "excesivamente marxista".

5. José Luís Varela, "Curros, a musa do proletariado rural galego, ¿era un poeta revolucionario?".

\section{Creación literaria (poemas)}

1. Celso Emilio Ferreiro, "Dez poemas sobre a longa noite dun amor perdido".

2. Federico García Lorca, "Media ducia máis de poemas galegos".

Cun prólogo de Ernesto Guerra da Cal e un epílogo de Eduardo Blanco Amor.

3. Uxío Novoneyra, "Oito glosas a unha cántiga semipopular".

A cantiga glosada era:

Eu irei a Santiago,

a Santiago de Galicia,

cando lumbriguen as luces

do imperio da Xusticia

4. Lorenzo Varela, "Gabanza da poesía épica e do primeiro verso da Eneida («Arma virumque cano...»)".

\section{Observacións finais}

Estas páxinas resumen a miña disertación proferida en Ourense (Deputación Provincial) o 30 de outubro de 2010 no marco dunha sesión plenaria (extraordinaria) da Real Academia Galega. A nosa institución trasladárase á cidade de Otero Pedrayo, Vicente Risco e Florentino L. Cuevillas para homenaxear a revista Nós 
no seu nonaxésimo aniversario (1920-2010). Utilicei, para redactar este escrito, as fichas que me serviron de guía naquela ocasión; na presente, precisei, ampliei ou maticei algúns datos, sempre no espírito daquel discurso, enteiramente contrafactual. De non terse producido a Guerra Civil, quizais a sociedade e a cultura galegas estarían ben representadas nese número da revista Nós publicado en 1951. Este "boletín mensual da cultura galega" expresaba ben, co seu pluralismo, o mapa intelectual e literario da Galicia daquel tempo, un pluralismo -todo hai que dicilo- cun inequívoco acento esquerdista, expresión, sen dúbida, da sociedade galega do ano 1951 (o que, quizais, podería ser e non foi). 